Research Article

\title{
Impact of Solvent Evaporation and Curing Protocol on Degree of Conversion of Etch-and-Rinse and Multimode Adhesives Systems
}

\author{
Ceci Nunes Carvalho ${ }^{D},{ }^{1}$ Marcos Daniel Septímio Lanza, ${ }^{2}$ Letícia Gomes Dourado, ${ }^{1}$ \\ Edilausson Moreno Carvalho, ${ }^{3}$ and José Bauer ${ }^{3}$ \\ ${ }^{1}$ School of Dentistry, CEUMA University, Rua Josué Montello No 1, Renascença II, 65075120 São Luís, MA, Brazil \\ ${ }^{2}$ Department of Restorative Dentistry, College of Dentistry, Federal University of Minas Gerais, \\ Presidente Antonio Carlos Av 6627, Pampulha, Belo Horizonte, MG, Brazil \\ ${ }^{3}$ Discipline of Dental Materials, School of Dentistry, University Federal of Maranhão (UFMA), Av. dos Portugueses, \\ 1966, 65085680 São Luis, MA, Brazil \\ Correspondence should be addressed to Ceci Nunes Carvalho; ceci.carvalho@ceuma.br
}

Received 27 November 2018; Revised 19 February 2019; Accepted 24 March 2019; Published 11 April 2019

Academic Editor: Ali I. Abdalla

Copyright ( 92019 Ceci Nunes Carvalho et al. This is an open access article distributed under the Creative Commons Attribution License, which permits unrestricted use, distribution, and reproduction in any medium, provided the original work is properly cited.

\begin{abstract}
Objectives. This study evaluated the effect of air-drying time and light-curing time on the degree of conversion (DC) of three etchand-rinse adhesive systems: ONE-STEP (OS) and ONE-STEP plus (OSP), Ambar (AMB), and two multimode adhesive systems: All-Bond Universal (ABU) and ScotchBond Universal (SBU) by Fourier transform infrared (FTIR) analysis. Materials and Methods. The DC of each adhesive system was analyzed with six experimental different protocols: (1) immediate light curing for $10 \mathrm{~s}$ without solvent volatilization; (2) $10 \mathrm{~s}$ solvent volatilization with air stream plus $10 \mathrm{~s}$ light curing; (3) $60 \mathrm{~s}$ solvent volatilization with air stream plus $10 \mathrm{~s}$ light curing; (4) immediate light curing for $20 \mathrm{~s}$ without solvent volatilization; (5) $10 \mathrm{~s}$ solvent volatilization with air stream plus $20 \mathrm{~s}$ light curing; and (6) $60 \mathrm{~s}$ solvent volatilization with air stream plus $20 \mathrm{~s}$ light curing. FTIR spectra were obtained, and the DC was calculated by comparing the ratio of aliphatic/aromatic double carbon bonds before and after light activation (Bluephase 20i). The DC means were analyzed by three-way analysis of variance (ANOVA) and post hoc Tukey tests $(\alpha=0.05)$. Results. Three-way ANOVA showed statistically significant adhesive, air-drying, and light-cured time $(p<0.001)$. In general, there was a trend of increased DC when the adhesives were dried and cured for longer times, but that was not observed for all the adhesives tested. The acetone-based adhesive systems require an air-drying prior to light activation. The light-curing time of $20 \mathrm{~s}$ increases the DC of all materials tested. Conclusion. The results suggested that the DC of the adhesive systems tested was material dependent. In general, the protocol with solvent evaporation for 10 seconds with air syringe plus 20 seconds of light curing finds the high values of DC.
\end{abstract}

\section{Introduction}

The development of adhesive systems has completely changed the traditional concepts of dentistry. Besides the complexity and number of steps involved with those application, researchers and manufacturers have aimed to simplify the clinical procedure by reducing the number of bonding steps and, thus, working time [1]. Most simple-to- use one-step adhesives contain a combination of hydrophilic and hydrophobic monomers, diluents, and photoinitiator systems, all provided in a single bottle solution containing ethanol or acetone as solvents [2,3].

The solvent has an important role on adhesive infiltration into the wet dentin substrate. The monomer interdiffusion has been demonstrated as the fundamental mechanism in achieving effective dentine bonding [4]. 
Therefore, the solvents should be completely removed during clinical application of the adhesive with an air-drying [5-7]. Otherwise, the remaining solvent in the adhesive may jeopardize polymerization due to the dilution of monomers and may result in voids and increase the permeability of the cured adhesive layer $[8,9]$. This might have an adverse effect on the performance of the resin-dentin bonds [6]. In the same way, the high solvent concentration within the adhesive layer prior to polymerization prevents the attainment of a high cross-linking polymer [10] and leads to pores between interfacial layers [11].

Clinicians should attempt to remove the highest amount of solvent to achieve an adequate monomer conversion [12]. It was previously demonstrated that extending the photoactivation time of simplified adhesives beyond those recommended by the manufacturers resulted in improved polymerization and reduced permeability, and it appeared to be a possible mean for improving the performance of these adhesives [13, 14]. There is no consensus; however, regarding the air-drying and polymerization time for 1-step self-etch or for 2-step etch-and-rinse, none have information about the new universal adhesive systems.

Thus, the aim of this study was to evaluate the DC of five adhesive systems after different solvent evaporations methods and curing time protocols by Fourier transform infrared (FTIR) analysis. The null hypothesis tested was that different protocols of air-drying and curing times would not result in significant differences in the DC of the adhesives tested.

\section{Materials and Methods}

The materials investigated were three etch-and-rinse adhesive systems: ONE-STEP (Bisco Inc., Schaumburg, IL, USA) and ONE-STEP Plus (Bisco Inc., Schaumburg, IL, USA), Ambar (FGM, Joinville, SC, Brazil), and two multimode adhesive systems: All-Bond Universal (Bisco Inc., Schaumburg, IL, USA) and ScotchBond Universal (3M/ ESPE, St. Paul, MN, USA). The chemical compositions, solvents, and manufacturers used in this study are listed in Table 1. Five experimental groups for each adhesive were formed according to different protocols of air-drying and curing times (Figure 1).

Solvent evaporation was performed at 3 bar using a pressure regulator, and the air nozzle was held at $90^{\circ}$ to the dentin surface at a distance of $20 \mathrm{~cm}$ distance from the sample. Samples were light cured either for $10 \mathrm{~s}$ or $20 \mathrm{~s}$, with a LED light-curing unit (Bluephase 20i/Ivoclar Vivadent Inc., Amherst, NY, USA) using the high curing mode, and at $5 \mathrm{~mm}$ from the sample surface.

2.1. DC Analysis. The DC was analyzed by the FTIR spectrometer (IRPrestige-21, Shimadzu Corporation, Kyoto, Japan) equipped with an attenuated total reflectance crystal (ATR-MIRacle ${ }^{\mathrm{TM}}$ Single Reflection Horizontal, Pike Technologies, Inc., Madison, WI, USA).

The absorption spectra of each uncured adhesive were obtained by placing two drops of each adhesive solution directly to the surface of the ATR diamond crystal. The absorption spectra of each cured adhesives specimens were obtained by dispensing two drops of the tested adhesive on an individual acetate strip, and it was subsequently air-dried and light-cured accordingly for each experimental group. After curing, the flat cured surface of the adhesive was firmly placed against the ATR crystal to collect the spectra. FTIR readings were carried out at $22 \pm 1^{\circ} \mathrm{C}$ with $50 \%$ relative humidity.

For the adhesive systems containing aromatic vinyl bonds of bisphenol and aliphatic bonds of the methacrylate functional group, the measurement of DC was done by evaluating the performance with the intensity of the spectra of the aromatic component band with the main peak around $1608 \mathrm{~cm}^{-1}$, relative to the band with the main absorbance peak of aliphatic carbon-to-carbon double bonds around $1638 \mathrm{~cm}^{-1}$, which changes with the polymerization of the composite [12].

Thus, for the adhesive systems ABU, AMB, OS, OSP, and $\mathrm{SBU}$, the spectra were obtained from the range between $1650 \mathrm{~cm}^{-1}$ and $1595 \mathrm{~cm}^{-1}$ with 30 scans at $4 \mathrm{~cm}^{-1}$ of resolution [14]. The DC (\%) was calculated using the following equation: DC $(\%)=100 \times\left[1-\left(R_{(\text {cured })} / R_{\text {(uncured) }}\right)\right] \quad[15]$, where $R$ represents the ratio between the absorbance peak around $1638 \mathrm{~cm}^{-1}$ and $1608 \mathrm{~cm}^{-1}$ (Figure 2).

Statistical analysis was performed using the SigmaPlot 13 software (SigmaPlot v. 13.0, Systat Software Inc., San Jose, USA). The normality and equality of variance assumptions were statistically analyzed by the Shapiro-Wilk test and Brown-Forsythe test. A three-way ANOVA (adhesive vs. airdrying vs. light-cured time) and Tukey's multiple comparisons test was used to analyze the data at a $\alpha=0.05$.

\section{Results}

The means and standard deviations of the degree of conversion (\%) values are presented in Table 2. Three-way ANOVA analysis showed that there were significant interactions between all three parameters $(F=7.65 ; p<0.001)$. The increase of light time and air-drying showed significant increases in DC for all tested adhesives (Table 2).

On the contrary, the degree of conversion of AMB and SBU was not influenced by the volatilization technique. In general, there was a trend of increased DC when the adhesives were dried (10-60 s) and cured for longer time (20s), but that was not observed for all the adhesives tested.

\section{Discussion}

The use of the air-drying has a fundamental role for the evaporation of the solvent in the adhesive systems. The application time, distance, and air pressure are variables that guide the behavior of adhesive systems. In general, when a higher air-drying pressure is used, the longer distance is indicated [16]. In this way, we chose the high constant air pressure (3 bar) and a large air distance for the material $(20 \mathrm{~cm})$ and analyze the time of the air-drying.

All adhesive systems used in the present study are simplified, and these materials have a large amount of 
TABLE 1: Composition, solvent, classification, manufacturer, and batch numbers of the adhesive systems used in this study.

\begin{tabular}{|c|c|c|c|c|c|}
\hline Adhesive systems & Composition & Solvent & Classification & Manufacturer & $\begin{array}{c}\text { Batch } \\
\text { numbers }\end{array}$ \\
\hline ONE-STEP (OS) & BPDM, HEMA, Bis-GMA & Acetone & $\begin{array}{l}\text { Etch-and- } \\
\text { rinse }\end{array}$ & $\begin{array}{c}\text { Bisco Inc., Schaumburg, } \\
\text { IL, USA }\end{array}$ & 1200013326 \\
\hline ONE-STEP Plus (OSP) & BPDM, HEMA, Dental Glass & Acetone & $\begin{array}{l}\text { Etch-and- } \\
\text { rinse }\end{array}$ & $\begin{array}{l}\text { Bisco Inc., Schaumburg, } \\
\text { IL, USA }\end{array}$ & 1200013362 \\
\hline Ambar (AMB) & $\begin{array}{l}\text { UDMA, HEMA, methacrylate acidic } \\
\text { monomers, methacrylate hydrophilic } \\
\text { monomers. }\end{array}$ & Ethanol & $\begin{array}{l}\text { Etch-and- } \\
\text { rinse }\end{array}$ & FGM, Joinville, SC, Brazil & 41210 \\
\hline $\begin{array}{l}\text { ScotchBond Universal } \\
\text { (SBU) }\end{array}$ & $\begin{array}{l}\text { MDP phosphate monomer, } \\
\text { dimethacrylate resins, HEMA, silane, } \\
\text { initiators, fillers }\end{array}$ & $\begin{array}{l}\text { Ethanol/ } \\
\text { water }\end{array}$ & Multimode & $\begin{array}{c}\text { 3M ESPE, St. Paul, MN, } \\
\text { USA }\end{array}$ & 497908 \\
\hline $\begin{array}{l}\text { All-Bond Universal } \\
\text { (ABU) }\end{array}$ & Bis-GMA, MDP monomers & Ethanol & Multimode & $\begin{array}{l}\text { Bisco Inc., Schaumburg, } \\
\text { IL, USA }\end{array}$ & 1300001314 \\
\hline
\end{tabular}

HEMA: 2-hydroxyethyl methacrylate; BPDM: biphenyl dimethacrylate; Bis-GMA: bisphenol A diglycidyl ether dimethacrylate; UDMA, urethane dimethacrylate. ${ }^{*}$ Source: manufacturer documentation.

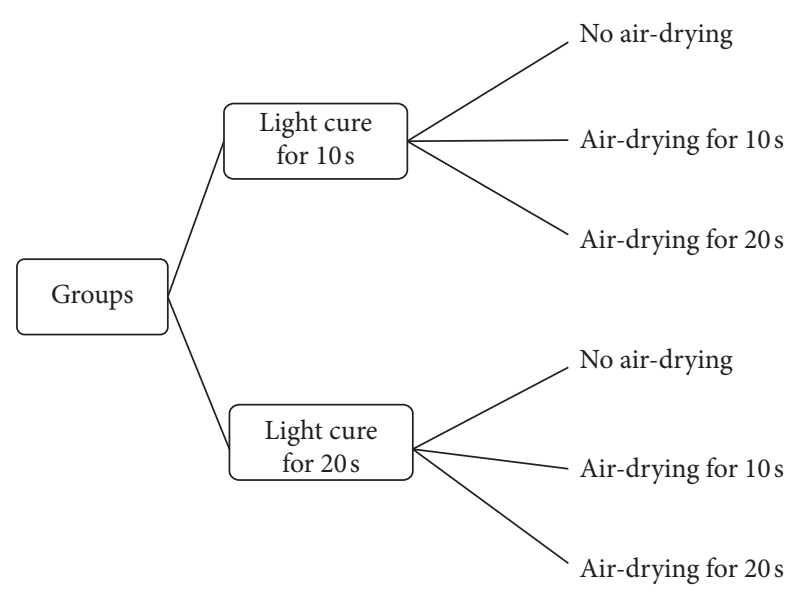

Figure 1: Experimental design.

solvent and hydrophilic monomers. Adhesive systems with large quantities of hydrophilic monomers are characterized by suboptimal polymerization [17] and hence the importance of increasing their degree of conversion with changing air-drying time and curing time. On the contrary, adhesive systems based on solvent-free hydrophobic monomers show a more complete polymerization [13].

Several studies have reported that solvents and water should be eliminated from the dentin surface before light curing with the air-drying procedure $[6,18,19]$. Some studies show that a short adhesive air-drying time (5-10 s) might be insufficient to obtain adequately durable bonding to dentin; instead, air-drying should be performed for longer periods (15-30s) [20, 21].

However, the results of this study showed that the DC of bonding agents did not depend solely as a function of the airdrying, and it depend also on the light cured time. Most of the adhesives tested in this study showed a high degree of conversion with the increase in the curing time and the airdrying. And, the highest values of DC were found with a curing time of $20 \mathrm{~s}$ and air-drying in $10 \mathrm{~s}$. So, the null hypothesis tested in this study was rejected because the degree of conversion of this adhesive was affected by different protocols of air-drying and curing times.
Besides, the increase of the curing time leads to a higher energy dose [22]. Some authors proposed to prolong the curing time beyond the time period recommended by the manufacturers $[13,23]$. These studies showed that by extending the curing times, the degree of conversion of adhesive could be improved. The increase of curing time can lead the heat generated from the curing unit also to facilitate solvent volatilization [12] that reduces the distance between the monomers [24] and increases the DC.

Previous study showed that air-drying had a significant effect on the evaporation of primer components, and that the degree of evaporation depends largely on the primer solvents employed [8]. The results showed that air-drying for a long time (10 s-60 s) resulted in significant increases in the DC for two acetone-based adhesives (OS, OSP) regardless of cured time. Acetone has a higher vapor pressure than ethanol and water [25]; for that reason, adhesives containing this acetone increase considerably their DC with increasing curing time and air-drying time.

Bail et al. [18] showed that longer solvent evaporation regimes were the most effective maneuvers in evaporating acetone-based adhesives, and this can optimize the degree of conversion and reduce the solubility/water sorption tendency. Some studies have shown the use of an air-drying to accelerate solvent evaporation [26], and this has an effect on the microtensile bond strength and mechanical properties of the adhesive system $[7,9,27]$.

Although all manufacturers indicate the air-drying step after applying bonding agents to evaporate water and solvents from the adhesive solution, some products tested in this study (AMB and SBU) were not influenced by evaporation methods, representing less sensitive materials for clinical use.

In the present study, different conversion degree values were found for adhesive systems with the same solvent. This may have occurred because of the different organic matrices present in these materials. These matrices may retain different amounts of solvent due to the polarity of the monomers. The resin polarity influences the number of hydrogen bonding sites and the attraction between the polymer and solvent [28]. Another way, ethanol-based adhesive ABU contains 30-60 wt.\% ethanol, whereas 


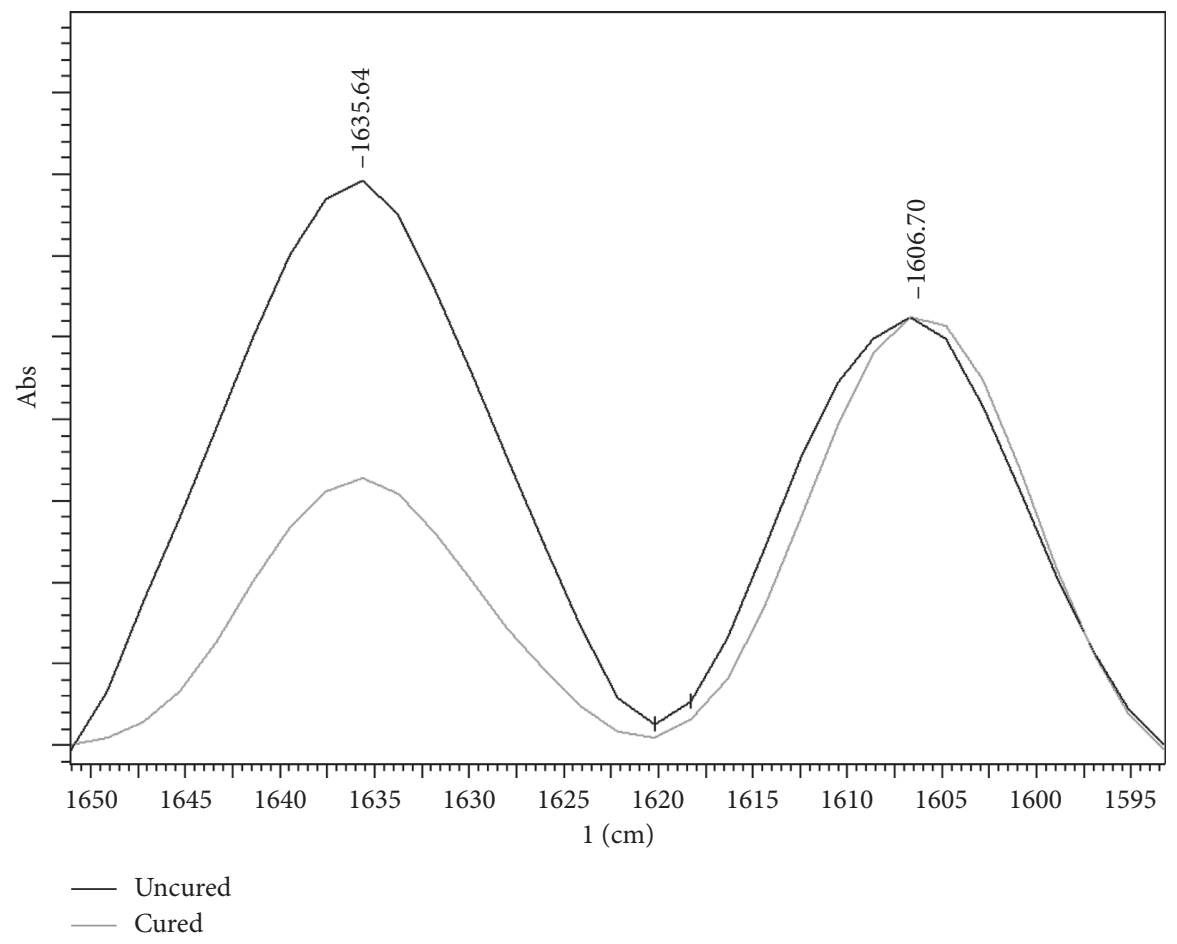

FIGURE 2: Intensity of the spectra of the Bis-GMA-based adhesive system.

TABLE 2: DC means and standard deviations (\%) of adhesive systems according to testing groups.*

\begin{tabular}{|c|c|c|c|c|c|c|}
\hline \multirow{2}{*}{ Adhesive system } & \multicolumn{3}{|c|}{ Light-curing time for $10 \mathrm{~s}$} & \multicolumn{3}{|c|}{ Light-curing time for $20 \mathrm{~s}$} \\
\hline & No air-drying & Air-drying for $10 \mathrm{~s}$ & Air-drying for $60 \mathrm{~s}$ & No air-drying & Air-drying for $10 \mathrm{~s}$ & Air-drying for $60 \mathrm{~s}$ \\
\hline $\begin{array}{l}\text { ONE-STEP } \\
\text { (OS) }\end{array}$ & $2.0(0.6)^{\mathrm{R}}$ & $10.9(5.5)^{\mathrm{P}, \mathrm{Q}, \mathrm{R}}$ & $27.0(4.8)^{\mathrm{L}, \mathrm{M}}$ & $14.0(1.2)^{\mathrm{O}, \mathrm{P}, \mathrm{Q}}$ & $27.9(6.9)^{\mathrm{L}, \mathrm{M}}$ & $38.1(4.1)^{\mathrm{J}, \mathrm{K}}$ \\
\hline $\begin{array}{l}\text { ONE-STEP Plus } \\
\text { (OSP) }\end{array}$ & $15.6(2.9)^{\mathrm{O}, \mathrm{P}, \mathrm{Q}}$ & $17.5(3.7)^{\mathrm{N}, \mathrm{O}, \mathrm{P}}$ & $31.1(1.1)^{\mathrm{K}, \mathrm{L}}$ & $21.7(1.3)^{\mathrm{M}, \mathrm{N}, \mathrm{O}}$ & $47.5(3.3)^{\mathrm{G}, \mathrm{H}, \mathrm{I}}$ & $47.9(2.7)^{\mathrm{F}, \mathrm{G}, \mathrm{H}, \mathrm{I}}$ \\
\hline $\begin{array}{l}\text { Ambar } \\
\text { (AMB) }\end{array}$ & $56.6(4.1)^{\mathrm{B}, \mathrm{C}, \mathrm{D}, \mathrm{E}, \mathrm{F}}$ & $54.8(2.0)^{\mathrm{C}, \mathrm{D}, \mathrm{E}, \mathrm{F}, \mathrm{G}}$ & $59.6(4.1)^{\mathrm{A}, \mathrm{B}, \mathrm{C}, \mathrm{D}}$ & $63.6(6.0)^{\mathrm{A}, \mathrm{B}, \mathrm{C}}$ & $63.7(2.3)^{\mathrm{A}, \mathrm{B}, \mathrm{C}}$ & $57.1(3.7)^{\mathrm{A}, \mathrm{B}, \mathrm{C}, \mathrm{D}, \mathrm{E}}$ \\
\hline $\begin{array}{l}\text { ScotchBond } \\
\text { Universal (SBU) }\end{array}$ & $40.3(4.8)^{\mathrm{I}, \mathrm{J}}$ & $42.8(1.0)^{\mathrm{H}, \mathrm{I}, \mathrm{J}}$ & $49.2(4.6)^{\mathrm{E}, \mathrm{F}, \mathrm{G}, \mathrm{H}, \mathrm{I}}$ & $65.7(4.2)^{\mathrm{A}}$ & $64.2(1.5)^{\mathrm{A}, \mathrm{B}}$ & $61.4(3.8)^{\mathrm{A}, \mathrm{B}, \mathrm{C}}$ \\
\hline $\begin{array}{l}\text { All-Bond } \\
\text { Universal (ABU) }\end{array}$ & $6.9(2.9)^{\mathrm{Q}, \mathrm{R}}$ & $17.6(3.0)^{\mathrm{N}, \mathrm{O}, \mathrm{P}}$ & $26.0(1.9)^{\mathrm{L}, \mathrm{M}, \mathrm{N}}$ & $37.0(4.7)^{\mathrm{J}, \mathrm{K}}$ & $51.7(4.4)^{\mathrm{D}, \mathrm{E}, \mathrm{F}, \mathrm{G}, \mathrm{H}}$ & $40.6(3.5)^{\mathrm{I}, \mathrm{J}}$ \\
\hline
\end{tabular}

* Means followed by different capital letters differ statistically by the Tukey test $(p<0.001)$.

SBU contains a lower concentration, 10-15 wt.\% [29]. The monomer concentration increases dramatically with the evaporation of ethanol, reducing the vapor pressure of the remaining ethanol $[30,31]$. This increase in monomer concentration prevents further solvent evaporation, resulting in residual ethanol being trapped inside the adhesive layer [25]. This explains the lower DC observed in our study for $\mathrm{ABU}$, which has a relatively high ethanol content [29].

For this reason, the optimal time of the evaporation solvent must be determined for each adhesive formulation in relation to the resin composition and solvent type. Even though a complete removal of the solvent is impossible, the evaporation should be maximized, and the adhesive layer must be air-dried to ensure adequate solvent evaporation [32].

\section{Conclusions}

The DC of the adhesive systems tested was material dependent. Air-drying for long time (10s-60s) is mandatory to acetone-based adhesives. The ethanol/water-based adhesive systems tested benefited from extended light cured time either with or without air application. One ethanol-based adhesive system tested (AMB) was not influenced by solvent evaporation techniques or by lightcuring time.

\section{Data Availability}

The data used to support the findings of this study are available from the corresponding author upon request. 


\section{Conflicts of Interest}

The authors certify that they have no proprietary, financial, or other personal interest of any nature or kind in any product, service, and/or company that is presented in this article.

\section{Acknowledgments}

The authors thank the Research Support for Scientific and Technological Development Foundation of Maranhão (FAPEMA-BEPP 01087/18), the National Council of Scientific and Technological Development (CNPq-237066/ 2012-2), and the CAPES for supporting this research. The authors would like to express their gratitude to GC Corporation, 3M/ESPE, and Bisco for kindly donating the materials.

\section{References}

[1] F. Ozer and M. B. Blatz, "Self-etch and etch-and-rinse adhesive systems in clinical dentistry," Compendium of Continuing Education in Dentistry, vol. 34, no. 1, pp. 12-30, 2013.

[2] K. L. Van Landuyt, J. Snauwaert, J. De Munck et al., "Systematic review of the chemical composition of contemporary dental adhesives," Biomaterials, vol. 28, no. 26, pp. 3757-3785, 2007.

[3] B. Van Meerbeek, K. Yoshihara, Y. Yoshida, A. Mine, J. De Munck, and K. L. Van Landuyt, "State of the art of selfetch adhesives," Dental Materials, vol. 27, no. 1, pp. 17-28, 2011.

[4] N. Nakabayshi and D. H. Pashley, Hybridization of Dental Hard Tissues, Quintessence, Tokyo, Japan, 1998.

[5] A. F. Reis, M. T. Oliveira, M. Giannini, M. F. De Goes, and F. A. Rueggeberg, "The effect of organic solvents on one-bottle adhesives' bond strength to enamel and dentin," Operative Dentistry, vol. 28, no. 6, pp. 700-706, 2003.

[6] C. A. Klein-Júnior, C. Zander-Grande, R. Amaral et al., "Evaporating solvents with a warm air-stream: effects on adhesive layer properties and resin-dentin bond strengths," Journal of Dentistry, vol. 36, no. 8, pp. 618-625, 2008.

[7] F. C. P. Garcia, J. C. F. Almeida, R. Osorio, R. M. Carvalho, and M. Toledano, "Influence of drying time and temperature on bond strength of contemporary adhesives to dentine," Journal of Dentistry, vol. 37, no. 4, pp. 315-320, 2009.

[8] T. Ikeda, J. De Munck, K. Shirai et al., "Effect of evaporation of primer components on ultimate tensile strengths of primeradhesive mixture," Dental Materials, vol. 21, no. 11, pp. 1051-1058, 2005.

[9] T. Ikeda, J. De Munck, K. Shirai et al., "Effect of air-drying and solvent evaporation on the strength of HEMA-rich versus HEMA-free one-step adhesives," Dental Materials, vol. 24, no. 10, pp. 1316-1323, 2008.

[10] B. Cho and S. H. Dickens, "Effects of the acetone content of single solution dentin bonding agents on the adhesive layer thickness and the microtensile bond strength," Dental Materials, vol. 20, no. 2, pp. 107-115, 2004.

[11] S. Dickens and B. Cho, "Interpretation of bond failure through conversion and residual solvent measurements and Weibull analyses of flexural and microtensile bond strengths of bonding agents," Dental Materials, vol. 21, no. 4, pp. 354-364, 2005.

[12] B. C. D. Borges, E. J. Souza-Junior, W. C. Brandt et al., "Degree of conversion of simplified contemporary adhesive systems as influenced by extended air-activated or passive solvent volatilization modes," Operative Dentistry, vol. 37, no. 3, pp. 246-252, 2012.

[13] M. Cadenaro, F. Antoniolli, S. Sauro et al., "Degree of conversion and permeability of dental adhesives," European Journal of Oral Sciences, vol. 113, no. 6, pp. 525-530, 2005.

[14] V. Miletic, P. Pongprueksa, J. De Munck, N. R. Brooks, and B. Van Meerbeek, "Monomer-to-polymer conversion and micro-tensile bond strength to dentine of experimental and commercial adhesives containing diphenyl(2,4,6trimethylbenzoyl)phosphine oxide or a camphorquinone/ amine photo-initiator system," Journal of Dentistry, vol. 41, no. 10, pp. 918-926, 2013.

[15] C. Pianelli, J. Devaux, S. Bebelman, and G. Leloup, "The micro-Raman spectroscopy, a useful tool to determine the degree of conversion of light-activated composite resins," Journal of Biomedical Materials Research, vol. 48, no. 5, pp. 675-681, 1999.

[16] F. S. El-Askary and R. Van Noort, "Effect of air-drying pressure and distance on microtensile bond strength of a self-etching adhesive," Journal of Adhesive Dentistry, vol. 13, no. 2, pp. 147-153, 2011.

[17] G. Marchesi, C. O. Navarra, M. Cadenaro et al., "The effect of ageing on the elastic modulus and degree of conversion of two multistep adhesive systems," European Journal of Oral Sciences, vol. 118, no. 3, pp. 304-310, 2010.

[18] M. Bail, J. Malacarne-Zanon, S. M. A. Silva et al., "Effect of airdrying on the solvent evaporation, degree of conversion and water sorption/solubility of dental adhesive models," Journal of Materials Science: Materials in Medicine, vol. 23, no. 3, pp. 629-638, 2012.

[19] V. Hass, I. Luque-Martinez, N. B. Sabino, A. D. Loguercio, and A. Reis, "Prolonged exposure times of one-step self-etch adhesives on adhesive properties and durability of dentine bonds," Journal of Dentistry, vol. 40, no. 12, pp. 1090-1102, 2012.

[20] P. H. D. B. Frota, A. Tanaka, A. D. Loguercio, D. M. Lima, C. N. Carvalho, and J. Bauer, "Effect of different times of solvent evaporation and $\mathrm{pH}$ in two self-etching adhesive systems on the shear bond strength of metallic orthodontic brackets," International Journal of Adhesion and Adhesives, vol. 50, pp. 223-227, 2014.

[21] M. M. Awad, A. Alrahlah, J. P. Matinlinna, and H. H. Hamama, "Effect of adhesive air-drying time on bond strength to dentin: a systematic review and meta-analysis," International Journal of Adhesion and Adhesives, vol. 90, pp. 154-162, 2019.

[22] S. Q. Ferreira, T. R. Costa, C. A. Klein-Júnior et al., "Improvement of exposure times: effects on adhesive properties and resin-dentin bond strengths of etch-and-rinse adhesives," Journal of Adhesive Dentistry, vol. 13, no. 3, pp. 235-241, 2011.

[23] L. Breschi, M. Cadenaro, F. Antoniolli et al., "Polymerization kinetics of dental adhesives cured with LED: correlation between extent of conversion and permeability," Dental Materials, vol. 23, no. 9, pp. 1066-1072, 2007.

[24] T. G. Nunes, F. C. P. Garcia, R. Osorio, R. Carvalho, and M. Toledano, "Polymerization efficacy of simplified adhesive systems studied by NMR and MRI techniques," Dental Materials, vol. 22, no. 10, pp. 963-972, 2006.

[25] E. L. Pashley, Y. Zhang, P. E. Lockwood, F. A. Rueggeberg, and D. H. Pashley, "Effects of HEMA on water evaporation from water-HEMA mixtures," Dental Materials, vol. 14, no. 1, pp. 6-10, 1998. 
[26] M. Giannini, C. A. G. Arrais, P. M. Vermelho, R. S. Reis, L. P. S. Santos, and E. R. Leite, "Effects of the solvent evaporation technique on the degree of conversion of one-bottle adhesive systems," Operative Dentistry, vol. 33, no. 2, pp. 149-154, 2008.

[27] I. V. Luque-Martinez, J. Perdigão, M. A. Muñoz, A. Sezinando, A. Reis, and A. D. Loguercio, "Effects of solvent evaporation time on immediate adhesive properties of universal adhesives to dentin," Dental Materials, vol. 30, no. 10, pp. 1126-1135, 2014.

[28] C. K. Y. Yiu, E. L. Pashley, N. Hiraishi et al., "Solvent and water retention in dental adhesive blends after evaporation," Biomaterials, vol. 26, no. 34, pp. 6863-6872, 2005.

[29] L. Chen and B. I. Suh, "Effect of hydrophilicity on the compatibility between a dual-curing resin cement and onebottle simplified adhesives," Journal of Adhesive Dentistry, vol. 15, no. 4, pp. 325-331, 2013.

[30] M. Cadenaro, L. Breschi, F. A. Rueggeberg et al., "Effects of residual ethanol on the rate and degree of conversion of five experimental resins," Dental Materials, vol. 25, no. 5, pp. 621-628, 2009.

[31] M. Cadenaro, L. Breschi, F. Antoniolli et al., "Degree of conversion of resin blends in relation to ethanol content and hydrophilicity," Dental Materials, vol. 24, no. 9, pp. 11941200, 2008.

[32] M. Cadenaro, T. Maravic, A. Comba et al., "The role of polymerization in adhesive dentistry," Dental Materials, vol. 35, no. 1, pp. e1-e22, 2019. 


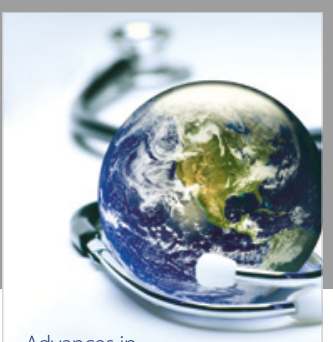

Advances in
Public Health

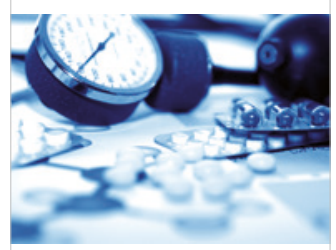

Case Reports in

Medicine

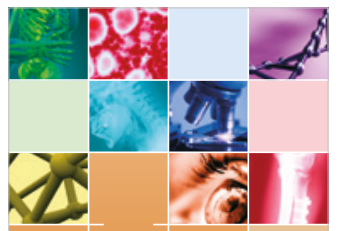

niernational Journal of

Biomaterials
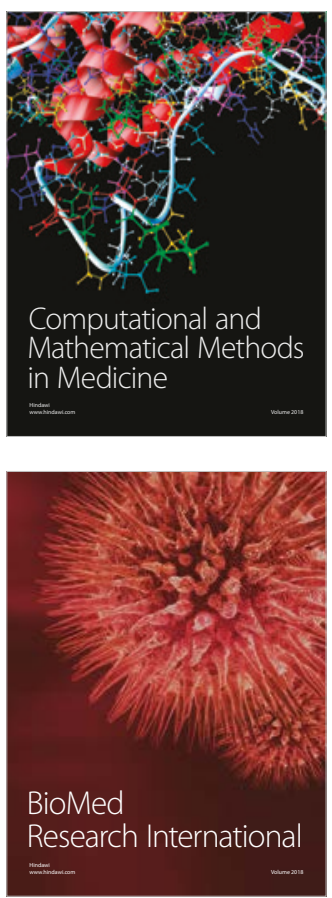

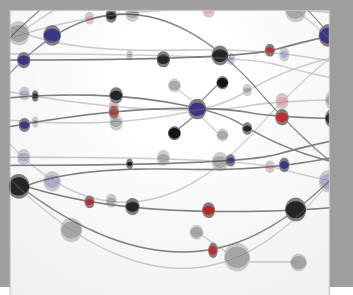

The Scientific World Journal Dentistry

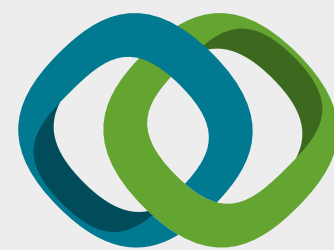

Hindawi

Submit your manuscripts at

www.hindawi.com
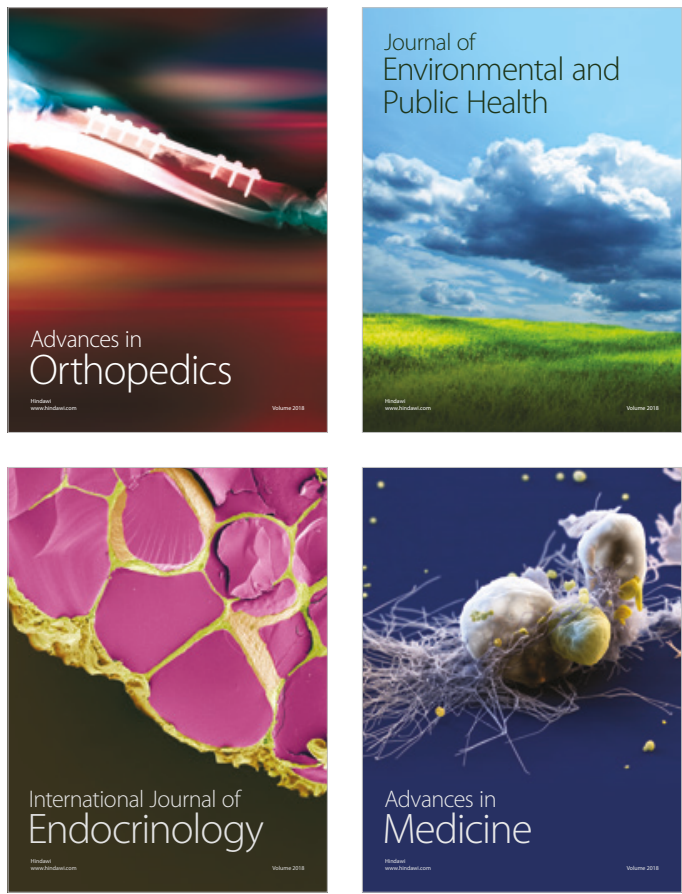
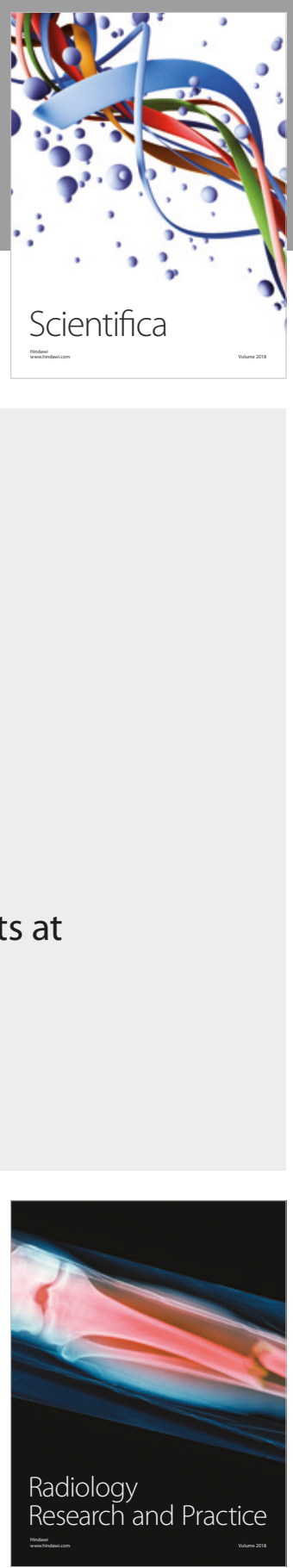

Scientifica

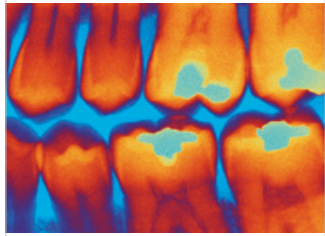

Case Reports in

Dentistry
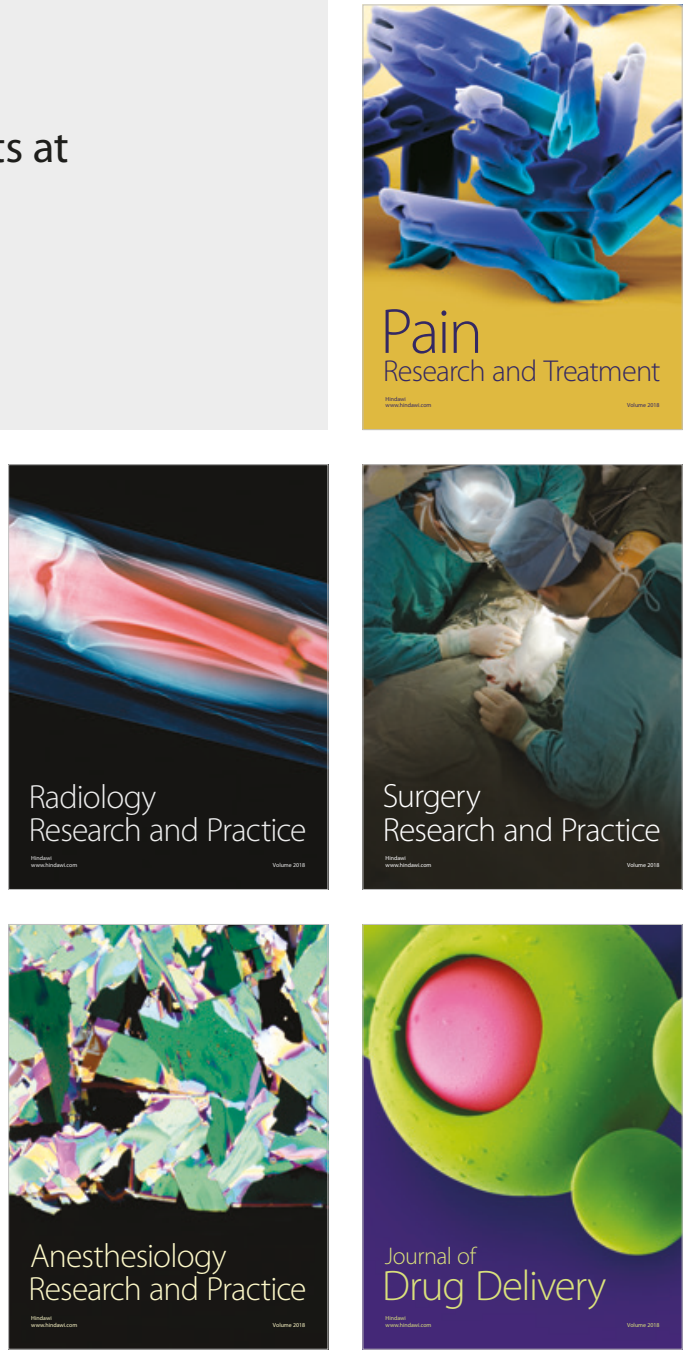